\title{
Real-life use of Rivaroxaban in the Netherlands: data from the Xarelto for Prevention of Stroke in Patients with Atrial Fibrillation (XANTUS) registry
}

\author{
R. Pisters ${ }^{1}$ - S. P. G. van Vugt ${ }^{2}$ M. A. Brouwer ${ }^{2}$ A. Elvan ${ }^{3}$ - W. L. ten Holt ${ }^{4}$ P. A. G. Zwart ${ }^{5}$ P. Kirchhof ${ }^{\text { }}$ \\ H. J. G. M. Crijns ${ }^{1}$ M. E. W. Hemels ${ }^{2,7}$
}

Published online: 3 July 2017

(C) The Author(s) 2017. This article is an open access publication.

\begin{abstract}
Background The Xarelto for Prevention of Stroke in Patients with Atrial Fibrillation (XANTUS) registry investigated the safety and efficacy of the factor Xa inhibitor rivaroxaban. We studied the Dutch XANTUS cohort to a ssess drug safety and prescription patterns in the Netherlands.

Methods The XANTUS registry was designed as a European prospective, observational study among patients with non-valvular atrial fibrillation. Major bleeding and all-cause mortality were assessed every three months during a 1-year follow-up period. In this Dutch sub-cohort we were also specifically interested in dosing regimens and the incidence and reasons for temporary or permanent discontinuation.

Results Patients $(n=899)$ had a mean age of $69(\mathrm{SD} \pm 9)$ years and $64.8 \%$ were male. The median $\mathrm{CHA}_{2} \mathrm{DS}_{2}$-VASc score was 2 (IQR 2-4) and the median HAS-BLED score
\end{abstract}

R. Pisters

r.pisters@mumc.nl

1 Department of Cardiology, Maastricht University Medical Centre, Maastricht, The Netherlands

2 Department of Cardiology, Radboud University Medical Centre, Nijmegen, The Netherlands

3 Department of Cardiology, Isala Hospital Zwolle, Zwolle, The Netherlands

4 Department of Cardiology, Amstelland Hospital, Amstelveen, The Netherlands

5 Department of Cardiology, Bernhoven Hospital, Uden, The Netherlands

6 Centre for Cardiovascular Sciences, University of Birmingham, Birmingham, UK

7 Department of Cardiology, Rijnstate Arnhem, Arnhem, The Netherlands was 2 (IQR 1-2). Major bleeding occurred in 19 patients (2.4 per 100 patient-years) and 8 patients (1.0 per 100 patient-years) died during the 1-year follow-up period. According to renal function, label-discordant dosing was observed in $48(8.3 \%)$ patients. Finally, 124 patients $(13.8 \%)$ reported a temporary interruption of rivaroxaban treatment and $11.8 \%$ switched to another oral anticoagulant therapy after permanent discontinuation of rivaroxaban.

Conclusion In the Dutch subset of the XANTUS registry, we observed low rates of major bleeding and label-discordant dosing and high persistence rates during one year of follow-up in patients receiving rivaroxaban in routine clinical practice. However, documenting the motivation of novel oral anticoagulant (NOAC) type and dose is essential to study label-discordant prescription, a potential safety paradox and identify patient characteristics to optimise NOAC use and adherence.

Keywords Atrial fibrillation - Rivaroxaban - XANTUS . Non-VKA oral anticoagulation

\section{Introduction}

The landscape concerning antithrombotic treatment of patients with non-valvular atrial fibrillation (AF) has changed in the last decade. First, anticoagulant treatment showed its superiority as compared with antiplatelet agents for stroke prevention [1-3]. Second, new oral anticoagulant agents have been approved as an alternative for vitamin $\mathrm{K}$ antagonists (VKAs) [4-7]. As a class, these agents, commonly referred to as non-VKA oral anticoagulants (NOACs), reduce the risk of intracranial haemorrhage by approximately $50 \%$ and of major bleeding by approximately $15 \%$ in comparison with VKA treatment [8]. Consequently, the recently 
updated European guidelines on the management of AF recommend the use of NOAC treatment over VKA treatment in eligible patients [9].

In the context of a long history of well-monitored VKA treatment, real-world data on compliance and management of complications were topics of interest at the time of the implementation of the NOACs. Therefore, at the request of the Dutch Ministry of Health, Welfare and Sports, a guidance document was published in November 2012 to facilitate a gradual implementation of the NOACs in daily clinical practice [10]. In accordance with other NOAC registries [11-15], in the Xarelto for Prevention of Stroke in Patients with Atrial Fibrillation (XANTUS) registry the investigators collected data on the safety of rivaroxaban in a 'realworld' setting. In addition, ischaemic complications, drug dosing and discontinuation rates were assessed [16]. In the present study, we evaluated the abovementioned outcome measures for the Dutch population of the XANTUS registry.

\section{Methods}

XANTUS is a European prospective, post-authorisation, observational phase IV study in patients with non-valvular AF treated with rivaroxaban for stroke prevention. Its design has been published previously [17].

\section{Study population and follow-up}

In brief, patients were eligible if they were diagnosed with non-valvular AF, started rivaroxaban therapy and provided written informed consent. All patients were screened sequentially and data were documented in an anonymous log file. Enrolment in the XANTUS registry took place between June 2012 and December 2013. For the purpose of this study we selected patients enrolled in the Netherlands. Decisions with regard to rivaroxaban prescription (e. g. dose selection, interruption and discontinuation) were at the discretion of the treating physician.

\section{Study outcomes}

The primary study outcomes were related to the safety of rivaroxaban and comprised major bleeding events and allcause mortality [16]. Major bleeding was defined according to the criteria suggested by the International Society of Thrombosis and Haemostasis (ISTH) [18]. A bleeding event was considered fatal when death occurred within 30 days of the bleeding event.

Secondary outcomes included clinically overt thromboembolic events (stroke, non-central nervous systemic embolism, transient ischaemic attack, myocardial infarction) and any non-major bleeding.

With regard to guideline adherence, we evaluated the dosing regimen in the perspective of renal function. Furthermore, we evaluated temporary and permanent discontinuation rates, including the reported reasons.

\section{Statistical considerations}

Given the exploratory purpose of the study, statistical analyses were descriptive. Data were depicted as means and standard deviations (SD) or medians and interquartile ranges (IQR), whichever was appropriate. Categorical variables were depicted as frequencies and percentages.

\section{Results}

\section{Baseline characteristics}

Among the 6784 participants of the XANTUS registry, a total of $899(13.3 \%)$ were enrolled in the Netherlands. The mean age of the Dutch patients was $69.2(\mathrm{SD} \pm 8.9)$ years and $583(64.8 \%)$ were male (Table 1$)$. With regard to risk scores, the median $\mathrm{CHA}_{2} \mathrm{DS}_{2}$-VASc score was 2 (IQR 2-4) and the median HAS-BLED score was 2 (IQR 1-2). Data concerning renal function were available in $580(64.5 \%)$ patients. A total of $53(5.9 \%)$ patients had a creatinine clearance of $<50 \mathrm{ml} / \mathrm{min}$.

Before enrolment in the registry, 779 patients $(86.7 \%)$ were using antithrombotic therapy, which included VKA in $576(64.1 \%)$ patients. Acetylsalicylic acid as monotherapy was reported in $120(13.3 \%)$ patients prior to treatment with rivaroxaban (Table 1 ).

With regard to follow-up, $764(85.0 \%)$ fulfilled the 1-year observation period.

\section{Study outcomes}

A total of 21 major bleeding events were observed in 19 $(2.1 \%)$ patients (Table 2). Bleeding events occurred most frequently in the gastrointestinal tract, followed by intracranial bleeding (Table 3). Gastrointestinal bleeding was reported 9 times in 7 patients. Fifteen patients reported unscheduled contact with a physician, in 10 patients medical intervention was necessary. With regard to all-cause mortality, a total of $8(0.9 \%)$ patients died during follow-up. Three deaths were considered to be caused by fatal bleeding and 2 were cardiovascular in origin. In addition, cancer, infectious disease and an unclassified cause were reported once.

Concerning the secondary outcomes, 15 thromboembolic events were reported in $13(1.4 \%)$ patients. These com- 
Table 1 Baseline characteristics of Dutch patients in the XANTUS study $(n=899)$

\begin{tabular}{|c|c|c|}
\hline Age (years), mean \pm SD & & $69.2 \pm 8.9$ \\
\hline & $\geq 75, n(\%)$ & $254(28.3 \%)$ \\
\hline Gender (male), $n(\%)$ & & $583(64.8 \%)$ \\
\hline Weight $(\mathrm{kg})$, mean $\pm \mathrm{SD}$ & & $85.8 \pm 17.1$ \\
\hline \multicolumn{3}{|l|}{ Creatinine clearance $(\mathrm{ml} / \mathrm{min}), n(\%)$} \\
\hline & $15-29$ & $5(0.6 \%)$ \\
\hline & $30-49$ & $48(5.3 \%)$ \\
\hline & $\geq 50$ & $527(58.6 \%)$ \\
\hline & Missing & $319(35.5 \%)$ \\
\hline \multicolumn{3}{|l|}{ Atrial fibrillation type, $n(\%)$} \\
\hline & First diagnosed & $170(18.9 \%)$ \\
\hline & Paroxysmal & $473(52.6 \%)$ \\
\hline & Persistent & $98(10.9 \%)$ \\
\hline & Permanent & $158(17.6 \%)$ \\
\hline \multirow[t]{3}{*}{$\mathrm{CHADS}_{2}$ score, median (IQR) } & & $1(1-2)$ \\
\hline & $<2$ & $556(61.8 \%)$ \\
\hline & $\geq 2$ & $343(38.2 \%)$ \\
\hline $\mathrm{CHA}_{2} \mathrm{DS}_{2}$-VASc score, median (IQR) & & $2(2-4)$ \\
\hline \multirow[t]{2}{*}{ HAS-BLED score, median (IQR) } & & $2(1-2)$ \\
\hline & $\geq 3$ & $161(17.9 \%)$ \\
\hline Prior stroke/TIA/non-CNS SE, $n(\%)$ & & $107(11.9 \%)$ \\
\hline Congestive heart failure, $n(\%)$ & & $58(6.5 \%)$ \\
\hline Hypertension, $n(\%)$ & & $550(61.2 \%)$ \\
\hline Coronary artery disease, $n(\%)$ & & $93(10.3 \%)$ \\
\hline Peripheral artery disease, $n(\%)$ & & $47(5.2 \%)$ \\
\hline Diabetes mellitus, $n(\%)$ & & $143(15.9 \%)$ \\
\hline \multirow[t]{4}{*}{ Prior use of antithrombotic therapy, $n(\%)$} & & $779(86.7 \%)$ \\
\hline & VKA & $559(62.2 \%)$ \\
\hline & Direct thrombin inhibitor & $14(1.6 \%)$ \\
\hline & ASA & $120(13.3 \%)$ \\
\hline
\end{tabular}

$S D$ standard deviation, $B M I$ body mass index, $I Q R$ interquartile range, TIA transient ischaemic attack, $C N S$ central nervous system, $S E$ systemic embolism, VKA vitamin K antagonist, $A S A$ acetylsalicylic acid Creatinine clearance calculated using the Cockcroft-Gault formula

\begin{tabular}{llll}
\hline & & $\begin{array}{l}\text { Incidence proportion, } \\
n(\%)\end{array}$ & $\begin{array}{l}\text { Incidence rate, events } \\
\text { per 100 patient-years } \\
(95 \% \mathrm{CI})\end{array}$ \\
\hline Primary outcomes & Major bleeding & $19(2.1 \%)$ & $2.4(1.4-3.7)$ \\
& All-cause mortality & $8(0.9 \%)$ & $1.0(0.4-2.0)$ \\
Secondary outcomes & Thromboembolic event & $13(1.4 \%)$ & $1.6(0.9-2.8)$ \\
& Non-major bleeding & $142(15.8 \%)$ & $19.6(16.5-23.1)$ \\
\hline
\end{tabular}

CI confidence interval prised 4 ischaemic strokes, 4 myocardial infarctions and 7 transient ischaemic attacks.

Any non-major bleeding occurred 195 times in 142 (15.8\%) patients (Table 3). A total of 68 patients reported unscheduled contact with a physician; subsequent medical intervention was taken in 26 patients. With regard to the impact of bleeding, patient discomfort (i. e. pain or impairment of daily life activities) was reported in 14 (73.7\%) cases with major bleeding events and in 38 (26.8\%) in patients with non-major bleeding complications.

\section{Rivaroxaban prescription and dosing regimens}

Rivaroxaban was prescribed in a dose of 20 milligrams $(\mathrm{mg})$ once daily in $817(90.8 \%)$ of the patients. These patients had a median HAS-BLED score of 2 (1-2) and $133(16.3 \%)$ had a HAS-BLED score $\geq 3$. Among the patients with a daily 
Table 3 Bleeding complications according to location

\begin{tabular}{lll}
\hline & & Number of patients $(\%)$ \\
\hline Major bleeding & & $19(2.1 \%)$ \\
& Gastrointestinal & $7(0.8 \%)$ \\
& Intracranial & $4(0.4 \%)$ \\
& Genitourinary & $2(0.2 \%)$ \\
& Conjunctival & $1(0.1 \%)$ \\
& Intraocular & $1(0.1 \%)$ \\
& Musculoskeletal & $1(0.1 \%)$ \\
Skn-major & Skin & $1(0.1 \%)$ \\
bleeding & Nurgery site & $1(0.1 \%)$ \\
& & $1(0.1 \%)$ \\
& Nasal reported & $142(15.8 \%)$ \\
& Genitourinary & $56(6.2 \%)$ \\
& Skin & $27(3.0 \%)$ \\
& Gastrointestinal & $21(2.3 \%)$ \\
& Other & $12(1.3 \%)$ \\
\hline
\end{tabular}

a
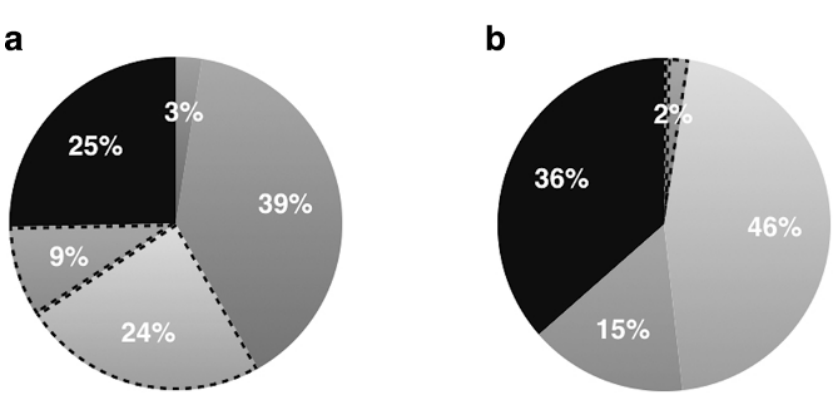

- $\mathrm{CrCl} 15-30$

CrCl 50-80

- $\mathrm{CrCl}$ missing

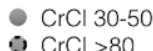

C $\mathrm{CrCl}>80$

- label discordant dose

$\mathrm{CrCl}$ : creatinine clearance in $\mathrm{ml} / \mathrm{min}$

Fig. 1 Renal function according to initially prescribed dose $\mathrm{CrCl}$ creatinine clearance

dose of $15 \mathrm{mg}$, the median HAS-BLED score was 2 (2-3) and $26(41.8 \%)$ had a HAS-BLED score $\geq 3$. The remaining 3 patients received an initial daily dose of $10 \mathrm{mg}$.

According to renal function, label-discordant dosing was observed in $48(8.3 \%)$ patients; 2 patients received a daily dose of $10 \mathrm{mg}, 26$ patients received $15 \mathrm{mg}$ discordantly and 20 patients received $20 \mathrm{mg}$ not according to label (Fig. 1). Major bleeding occurred in 17 (2.1\%) and 2 (2.5\%) patients treated with rivaroxaban $20 \mathrm{mg}$ and $15 \mathrm{mg}$, respectively.

\section{Discontinuation rates}

During follow-up, 124 patients $(13.8 \%)$ reported a temporary interruption of rivaroxaban treatment. Reasons included surgery $(n=60)$, bleeding $(n=35)$ and non-bleeding adverse events $(n=29)$. The median duration of interruption was 3 days (IQR 2-8).

Study treatment was discontinued in $147(16.4 \%)$ patients, half of whom discontinued within 3 months after initiation (Fig. 2). The main documented reasons for permanent discontinuation were patient decision $(n=33,23 \%)$ or an adverse event ( $n=27,19 \%)$ (Fig. 2a). The majority of patients $(n=84)$ who stopped study treatment switched to VKAs, followed by a switch to a different NOAC ( $n=$ 22).

\section{Discussion}

\section{Main outcomes and patient population}

In this substudy of the XANTUS registry we assessed the safety of rivaroxaban in a 'real-world' situation in the Netherlands. The Dutch subgroup consisted of less permanent AF patients compared with the overall XANTUS cohort [16]. Subsequently, this largely explains the observed differences in patient characteristics between the two cohorts, i. e. a younger and healthier Dutch subgroup. The inclusion of more paroxysmal AF patients in the Netherlands likely relates to national policy which advocates the initial use of NOACs in first detected AF opposed as to actively switching patients from VKAs to NOACs. Among the 899 patients major bleeding rates, which have been published previously, were low and comparable with the overall XANTUS cohort. Similar observations were made for the rates of thromboembolic events and all-cause mortality [16]. Furthermore, we observed that over $90 \%$ of patients were treated according to label in daily clinical practice, and that 1 -year persistence rate was over $80 \%$.

Major bleeding events were observed less frequently than in the overall XANTUS cohort (2.1/100 patient-years) and the ROCKET-AF study (3.5/100 patient-years). In both the overall XANTUS cohort and the Dutch subset over $40 \%$ of the major bleeding complications had a gastrointestinal origin. Among the patients randomised to rivaroxaban treatment in the ROCKET-AF trial, gastrointestinal bleeding comprised over 50\% (224/395) of the major bleeding complications. The event rate for intracranial haemorrhage, often considered to be the most devastating bleeding complication, accounted for $20 \%$ of the major bleeding complications in both the overall and the Dutch XANTUS cohort, as compared with $15 \%$ in the ROCKET-AF trial population.

With regard to ischaemic complications and mortality, event rates in the Dutch XANTUS cohort were low compared with the ROCKET-AF population. The differences in event rates for ischaemic stroke ( 0.5 vs $1.4 / 100$ patient-years) and all-cause mortality (1.0 vs $1.9 / 100$ patientyears) might be explained by important differences in base- 
Fig. 2 Permanent (a) and temporary (b) reason of discontinuation among patients who stopped study treatment a

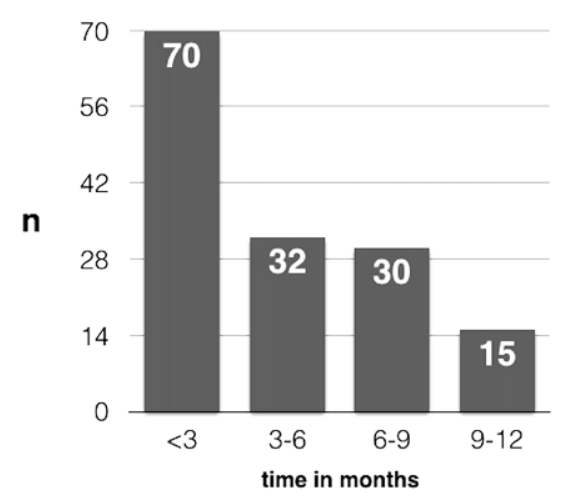

b

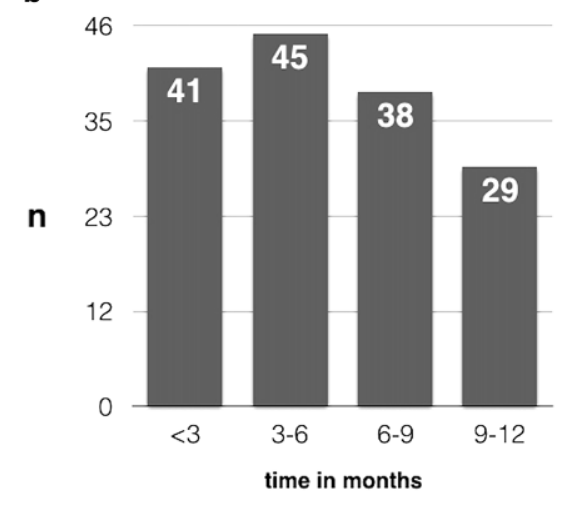

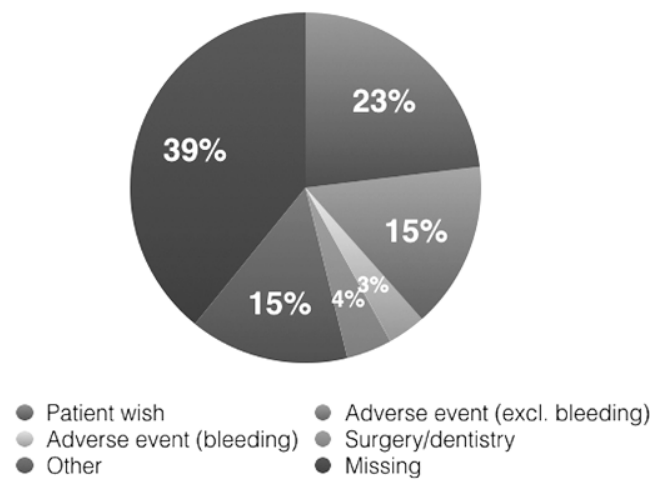

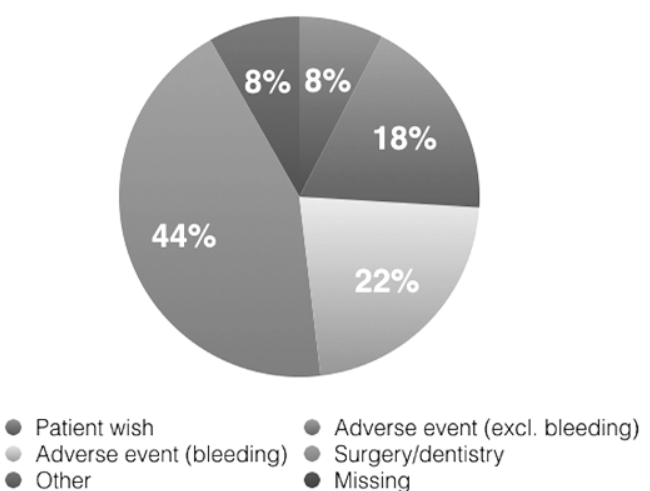

line characteristics. Of the Dutch XANTUS patients, $28 \%$ were aged 75 years or over, which is less than in the overall XANTUS cohort $(38 \%)$ or ROCKET-AF population $(43 \%)$. Among the ROCKET-AF population, all patients had a $\mathrm{CHADS}_{2}$ score of at least 2 points. In contrast, only $38 \%$ of the Dutch XANTUS patients had a $\mathrm{CHADS}_{2}$ score $\geq 2$. As for renal function, $6 \%$ had a creatinine clearance below $50 \mathrm{ml} / \mathrm{min}$, whereas these percentages were $9 \%$ and $20 \%$ for the overall XANTUS and ROCKET-AF cohorts, respectively. Note that the ROCKET-AF trial intended to include a high-risk population. As such, the inclusion criteria were different from the XANTUS registry. Initial prescription of NOACs in a low-risk population is in line with the recommendations of the Dutch Ministry of Health, Welfare and Sport, proposing a careful introduction of NOACs in the Netherlands. Noteworthy, most treatment switches from rivaroxaban were to VKAs (84/143), indicating the relative novelty of NOACs during the study period. In addition, the gradual uptake of NOAC treatment in the Netherlands has been described recently [19].

\section{Dosing issues}

In $8 \%$ of the Dutch XANTUS participants, rivaroxaban was prescribed in an inappropriate dose. As stated in the summary of product characteristics (SmPC), dose recommen- dations are particularly based upon renal function. However, prescribing physicians were probably influenced by other factors. First, previous guidelines recommended the lower NOAC dose for patients with a HAS-BLED score $\geq 3$ [20]. Current guidelines do not recommend dose reductions based on bleeding risk scores [9].

It is important to state that the rationale behind the dosereduction strategies in the randomised trials was to avoid overdosing in specific patient groups. In a recently published sub-analysis of the ARISTOTLE trial, the authors state that inappropriate dosing could lead to preventable ischaemic strokes and that patients therefore should be treated with the studied dose [21]. A similar statement is found in the European Society of Cardiology guidelines on AF management [9]. Consequently, other perceived bleeding risk factors, including a prior bleeding event or concomitant use of antiplatelet agents, should not per se lead to prescription of a reduced dose. With regard to prior bleeding, exploratory data from the RE-LY trial did not support a dose-lowering strategy after a bleeding episode [22].

Nevertheless data on creatinine clearance were missing in over one-third of the patients. Whether this is because of clinical judgment (no need to measure the creatinine clearance) or due to the observational nature of the study (not reported) remains speculative. The observed low rates of stroke and bleeding and limited use of low-dose rivarox- 
aban support the former. Dose reduction during follow-up was uncommon, perhaps this is due to limited follow-up of creatinine clearance measurements or to the relatively low risk profile of the population.

All in all, these data advocate to prescribe NOACs in doses as evaluated in trial settings and be aware of the safety paradox: a lower (N)OAC dose does not equal a low(er) risk of bleeding and preserved efficacy [22, 23].

\section{Discontinuation}

Despite good treatment satisfaction, 1 out of 6 patients permanently discontinued treatment with rivaroxaban during the follow-up period, with a peak during the first quarter. Although the motivation for discontinuation of rivaroxaban was missing in a substantial number of patients, patient decisions and adverse events were reported. Nonetheless, a persistence rate over $80 \%$ was reported in the Dresden registry as well, in which bleeding complications and nonbleeding side effects accounted for the majority of treatment discontinuations [24].

The majority of patients (106/147) switched to either VKA treatment $(n=84)$ or another NOAC $(n=22)$ after rivaroxaban discontinuation. The relatively high number of patients switching to VKA treatment should be placed in a time perspective. The remaining patients might have had a temporary indication for anticoagulation therapy. Given the considerable proportion of paroxysmal $\mathrm{AF}$ and young (e. g. $<65$ years of age) patients together with a $\mathrm{CHA}_{2} \mathrm{DS}_{2}$ VASc score of 0 or 1 , this temporary indication could be related to a rhythm control strategy (e. g. peri-ablation or cardioversion). Despite the relatively high percentage $(13 \%)$ of patients treated with antiplatelet therapy for stroke prevention before study entry, observations from this study were reassuring, as a switch from rivaroxaban to antiplatelet therapy was uncommon $(<1 \%)$. Treatment was interrupted temporarily in $13.8 \%$ of the patients in the study cohort, a proportion slightly higher compared with the overall XANTUS cohort $(8.8 \%)$. As compared with the ROCKET-AF population (2165/7131 patients treated with rivaroxaban) interruption rates were similar, as were the main reasons for interruption, which included surgery and bleeding events [25].

\section{Limitations}

Although the first real-world data concerning NOAC use in the Netherlands are very valuable, they should be interpreted in the context of guideline recommendations at the time the study was conducted (2012-2013). At present, NOACs are prescribed more liberally, and the current ESC guideline has endorsed NOACs as the preferred treatment
[9]. Second, we should acknowledge that data on renal function were not available at the time of prescribing rivaroxaban in one-third of the patients. Again, this observation deserves particular clinical attention as dose reduction in the ROCKET-AF randomised controlled trial (RCT) and dose recommendations in the SmPC rely particularly on renal function. Finally, the study cohort was a relatively healthy population. Initial selection of patients even more healthy than in the respective RCT is common with the introduction of new drugs. Although this exemplifies reallife, we must be aware of underrepresentation of subgroups of patients in an RCT and 'real-life' setting. For instance, whether the observations can be extrapolated to a very highrisk population is questionable. This question will probably be answered by the randomised FRAIL-AF trial, which will be conducted in the Netherlands [26].

\section{Conclusion}

In the Dutch subset of the XANTUS registry, we observed low rates of major bleeding and label-discordant dosing and high persistence rates during one year of follow-up in patients receiving rivaroxaban in routine clinical practice. However, documenting the motivation of NOAC type and dose is essential to study label-discordant prescription, a potential safety paradox and identify patient characteristics to optimise NOAC use and adherence.

Acknowledgements The authors wish to thank Ingrid Meeuwsen (Bayer) for her help in providing the study data. The authors wish to thank the participating centres in the N: Isala Klinieken (Zwolle), St Elisabeth Hospital (Tilburg), Radboud UMC (Nijmegen), Jeroen Bosch Hospital (Den Bosch), Antonius Hospital (Sneek), VieCuri Medisch Centrum (Venlo), Isala Diaconessenhuis (Meppel), Zuyderland Medisch Centrum (Heerlen), Spaarne Gasthuis (Haarlem), Rijnstate Hospital (Arnhem), Refaja Hospital (Stadskanaal), Sint Franciscus Gasthuis (Rotterdam), Amstelland Hospital (Amstelveen), Hospital Bernhoven (Uden), BovenIJ Hospital (Amsterdam), Spaarne Hospital (Hoofddorp), Maxima Medisch Centrum (Veldhoven), Vlietland Hospital (Schiedam), St. Antonius Hospital (Nieuwegein), Ropcke-Zweers Hospital (Hardenberg), De Slonsberg (Dokkum), Ijsselland Hospital (Capelle a/d Ijssel), Gelderse Vallei Hospital (Ede).

Funding The XANTUS registry was supported by Bayer HealthCare Pharmaceuticals and Janssen Research \& Development, LLC. No funds were received in support of this sub-analysis. No benefits in any form have been or will be received from a commercial party related directly or indirectly to the subject of this manuscript. The authors have no financial interest in the subject of this article.

Conflict of interest R. Pisters, S.P.G. van Vugt, M.A. Brouwer, A. Elvan, W.L. ten Holt, P.A.G. Zwart, P. Kirchhof, H.J.G.M. Crijns and M.E.W. Hemels declare that they have no competing interests.

Open Access This article is distributed under the terms of the Creative Commons Attribution 4.0 International License (http:// creativecommons.org/licenses/by/4.0/), which permits unrestricted use, distribution, and reproduction in any medium, provided you give 
appropriate credit to the original author(s) and the source, provide a link to the Creative Commons license, and indicate if changes were made.

\section{References}

1. Connolly SJ, Eikelboom J, Joyner C, et al. Apixaban in patients with atrial fibrillation. N Engl J Med. 2011;364:806-17.

2. Connolly S, Pogue J, Hart R, et al. Clopidogrel plus aspirin versus oral anticoagulation for atrial fibrillation in the Atrial fibrillation Clopidogrel with Irbesartan for prevention of Vascular Events (ACTIVE W): a randomised controlled trial. Lancet. 2006;367:1903-12.

3. Mant J, Hobbs FD, Fletcher K, et al. Warfarin versus aspirin for stroke prevention in an elderly community population with atrial fibrillation (the Birmingham Atrial Fibrillation Treatment of the Aged Study, BAFTA): a randomised controlled trial. Lancet. 2007;370:493-503.

4. Connolly SJ, Ezekowitz MD, Yusuf S, et al. Dabigatran versus warfarin in patients with atrial fibrillation. N Engl J Med. 2009;361:1139-51.

5. Granger CB, Alexander JH, McMurray JJ, et al. Apixaban versus warfarin in patients with atrial fibrillation. N Engl J Med. 2011;365:981-92.

6. Giugliano RP, Ruff CT, Braunwald E, et al. Edoxaban versus warfarin in patients with atrial fibrillation. N Engl J Med. 2013;369: 2093-104.

7. Patel MR, Mahaffey KW, Garg J, et al. Rivaroxaban versus warfarin in nonvalvular atrial fibrillation. N Engl J Med. 2011;365:883-91.

8. Ruff CT, Giugliano RP, Braunwald E, et al. Comparison of the efficacy and safety of new oral anticoagulants with warfarin in patients with atrial fibrillation: a meta-analysis of randomised trials. Lancet. 2014;383:955-62.

9. Kirchhof P, Benussi S, Kotecha D, et al. 2016 ESC guidelines for the management of atrial fibrillation developed in collaboration with EACTS: the Task Force for the management of atrial fibrillation of the European Society of Cardiology (ESC). Developed with the special contribution of the European Heart Rhythm Association (EHRA) of the ESC Endorsed by the European Stroke Organisation (ESO). Eur Heart J. 2016;37:2893-962. doi:10.1093/eurheartj/ ehw210.

10. CVGK. Guidance document: guided introduction NOACs 2012. http://www.cvgk.nl/d/995/leidraad-begeleide-introductie-noacs. Accessed 3-10-2016.

11. Kirchhof P, Ammentorp B, Darius H, et al. Management of atrial fibrillation in seven European countries after the publication of the 2010 ESC guidelines on atrial fibrillation: primary results of the PREvention oF thromboemolic events - European Registry in Atrial Fibrillation (PREFER in AF). Europace. 2014;16:6-14.

12. Kakkar AK, Mueller I, Bassand JP, et al. Risk profiles and antithrombotic treatment of patients newly diagnosed with atrial fibrillation at risk of stroke: perspectives from the international, observational, prospective GARFIELD registry. PLOS ONE. 2013;8:e63479.

13. Huisman MV, Rothman KJ, Paquette M, et al. Antithrombotic treatment patterns in patients with newly diagnosed nonvalvular atrial fibrillation: the GLORIA-AF registry, phase II. Am J Med. 2015;128:1306-1313.e1.

14. Lip GY, Laroche C, Ioachim PM, et al. Prognosis and treatment of atrial fibrillation patients by European cardiologists: one year follow-up of the EURObservational Research Programme-Atrial Fibrillation General Registry Pilot Phase (EORP-AF Pilot registry). Eur Heart J. 2014;35:3365-76.

15. Yao X, Abraham NS, Sangaralingham LR, et al. Effectiveness and safety of dabigatran, rivaroxaban, and apixaban versus warfarin in nonvalvular atrial fibrillation. J Am Heart Assoc. 2016;5(6):e003725.

16. Camm AJ, Amarenco P, Haas S, et al. XANTUS: a real-world, prospective, observational study of patients treated with rivaroxaban for stroke prevention in atrial fibrillation. Eur Heart J. 2016;37:1145-53.

17. Camm AJ, Amarenco P, Haas S, et al. XANTUS: rationale and design of a noninterventional study of rivaroxaban for the prevention of stroke in patients with atrial fibrillation. Vasc Health Risk Manag. 2014;10:425-34.

18. Schulman S, Kearon C. Definition of major bleeding in clinical investigations of antihemostatic medicinal products in non-surgical patients. J Thromb Haemost. 2005;3:692-4.

19. Ten Cate V, Ten Cate H, Verheugt FW. The Global Anticoagulant Registry in the FIELD-Atrial Fibrillation (GARFIELD-AF): exploring the changes in anticoagulant practice in patients with non-valvular atrial fibrillation in the Netherlands. Neth Heart J. 2016;24(10):574-80. doi:10.1007/s12471-016-0874-y.

20. Camm AJ, Lip GY, De Caterina R, et al. 2012 focused update of the ESC Guidelines for the management of atrial fibrillation: an update of the 2010 ESC guidelines for the management of atrial fibrillation. Developed with the special contribution of the European Heart Rhythm Association. Eur Heart J. 2012;33:2719-47.

21. Alexander JH, Andersson U, Lopes RD, et al. Apixaban $5 \mathrm{mg}$ twice daily and clinical outcomes in patients with atrial fibrillation and advanced age, low body weight, or high creatinine: a secondary analysis of a randomized clinical trial. JAMA Cardiol. 2016;1:673-81.

22. Beasley BN, Unger EF, Temple R. Anticoagulant options - why the FDA approved a higher but not a lower dose of dabigatran. N Engl J Med. 2011;364:1788-90.

23. Hylek EM, Go AS, Chang Y, et al. Effect of intensity of oral anticoagulation on stroke severity and mortality in atrial fibrillation. N Engl J Med. 2003;349:1019-26.

24. Beyer-Westendorf J, Forster K, Ebertz F, et al. Drug persistence with rivaroxaban therapy in atrial fibrillation patients-results from the Dresden non-interventional oral anticoagulation registry. Europace. 2015;17:530-8.

25. Sherwood MW, Douketis JD, Patel MR, et al. Outcomes of temporary interruption of rivaroxaban compared with warfarin in patients with nonvalvular atrial fibrillation: results from the rivaroxaban once daily, oral, direct factor Xa inhibition compared with vitamin $\mathrm{K}$ antagonism for prevention of stroke and embolism trial in atrial fibrillation (ROCKET AF). Circulation. 2014;129:1850-9.

26. ZonMw. Optimising anticoagulant management in frail elderly patients with AF: the FRAIL-AF study 2016. http://www.zonmw.nl/ $\mathrm{nl} /$ projecten/project-detail/optimising-anticoagulant-managementin-frail-elderly-patients-with-af-the-frail-af-study/samenvatting/. Accessed 3-10-2016. 


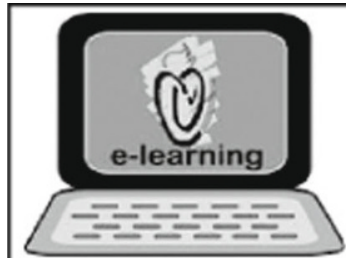

\section{CVOI E-learning formula!}

This is the CVOI e-learning article. The author has prepared 10 questions which are available through the website of the Cardiovascular Educational Institute (CVOI). Please follow the instructions below.

After finishing the questions you will be asked to fill in your name, hospital and e-mail address; then press the button 'verzenden'.

When 6 out of the 10 questions are answered correctly, you acquire 1 accreditation point granted by the Quality Committee of the Netherlands Society of Cardiology (NVVC). The acquired point will be credited to your personal file in the GAIA system. You will also receive an e-mail with all the correct answers.

Over a period of one year 10 e-learning articles will appear in 10 subsequent NHJ editions. In each edition the e-learning article will be recognisable by a special icon. On an annual basis you can collect 10 accreditation points. The accreditation points are credited in the GAIA system by the CVOI.

If you need additional information, please contact the CVOI by e-mail: cvoi@cvoi.org or by phone: 030-2345001.

J. J. Piek

Chief editor NHJ
K.B. Schick

Coordinator CVOI 